\title{
Predictive value of serum lactate dehydrogenase in head injury
}

\author{
C. J . R A O, P. K. S H U K L A, S. M O H A N T Y, \\ A N D Y. J. V. R E D D Y \\ From the Departments of Neurosurgery and Pathology, Institute of Medical Sciences, \\ Banaras Hindu University, Varanasi, India
}

S U M MAR Y Serum total lactate dehydrogenase (LDH) was estimated serially for up to 15 days in 110 patients with head injuries who had no extraneural injury. Increase in LDH activity generally indicated the degree of parenchymal brain damage. The prognostic value of LDH was established by correlating its activity with clinical criteria such as duration of unconsciousness and post-traumatic amnesia, type of brain damage, and quality of survival. A significant rise in LDH activity suggested severe brain damage and poor prognosis.

The factors operating on the brain in head injury are multiple and complex, and assessment of the extent of brain damage and prediction of outcome are difficult in the early stages. Patients with different degrees of brain injury, as judged by their final condition, may at first show a similar or identical clinical picture (Lancet editorial, 1973). Clinical (Jennett and Bond, 1975; Mohanty et al., 1977), biochemical (King et al., 1974; Patra, 1977), and electrophysiological (Tandon et al., 1972) studies have proved useful in estimating the prognosis in head injury. But sometimes the real extent of primary brain damage is masked by traumatic brain oedema and cerebral metabolic derangement.

In recent years some encouraging reports have appeared on assessing the degree of brain damage by estimating serum and cerebrospinal fluid enzymes such as lactic dehydrogenase (Lindblom and Aberg, 1972; Thomas and Rowan, 1976), creatine phosphokinase (Rabow et al., 1971), glutamic oxalacetic transaminase (Lindblom and Aberg, 1972), and cholinesterase (Rao, Shukla, Mohanty, and Reddy, unpublished). There are no reports, however, on the significance of lactic dehydrogenase (LDH) in predicting the outcome by correlating blood levels with clinical criteria such as duration of unconsciousness and posttraumatic amnesia.

Address for reprint requests: Dr S. Mohanty, Department of Neurosurgery, Institute of Medical Sciences, Banaras Hindu University, Varanasi-221005, India.

Accepted 17 May 1978

\section{Patients and methods}

Serum total lactate dehydrogenase (LDH) activity was estimated by King's colorimetric method 0 (Wooton, 1964) in 110 cases of acute head injury? without any other extraneural injury. Soon after 8 admission all patients underwent thorough examination of the nervous and other systems. Any patient revealing extracerebral injury, either at admission or on subsequent follow-up, was excluded from the study. A colorimetric method was found to be simpler than, and as good as, a spectrophotometric procedure (Varley, 1969; Dharker et al., 1976; Shukla et al., 1977). Initial venous blood samples were obtained on the day of injury and successive samples were collected for periods of two to four days, five to nine days, and 10 to 15 days for estimation of LDH.

The head injury patients were classified in four groups: (1) concussion $(n=48),(2)$ extracerebral haematoma $(n=8)$, (3) intracerebral damagelaceration and haematoma $(n=39)$, and (4) brainstem injury-primary and secondary- $(n=15)$. Patients were classified as having brainstem injury when they had decerebrate rigidity, pupillary changes, and marked autonomic disturbances. Where these clinical features were manifested after a lucid interval and were associated with either intracranial haematoma or cerebral oedema, they were regarded as being caused by secondary brainstem injury. However, if the brainstem disturbances were evident immediately after injury and no obvious cerebral compression was detected, 
cases were classified as primary brainstem injury and diffuse white matter injury. The pathological diagnosis was confirmed by clinical examination, investigations, operative or necropsy findings. Patients were also grouped according to duration of unconsciousness (less than one hour, one hour to one day, and more than one day) and posttraumatic amnesia (less than one hour, one hour to one day, one day to one week, and more than one week). Outcome, reviewed for periods up to three months from injury, was specified as (1) dead, (2) severely disabled, (3) moderately disabled, or (4) good, as described by Jennett and Bond (1975). In the concussion group, 36 patients made a good survival, 10 were moderately disabled, one was severely disabled, and one died. In the extracerebral haematoma group, three patients were in the good survival category, two were moderately and one severely disabled, and two died. The quality of survival in the intracerebral damage group consisted of six with good survival, 18 moderately and 10 severely disabled, and five dead. In the brainstem injury group, there was no good survival, three patients were moderately disabled, five severely disabled, and seven patients died. A parallel study on 30 neurologically normal people formed the basis of normal control values. Serum total LDH was also estimated preoperatively from 10 patients with brain tumour (six supratentorial and four infratentorial), and the values were compared with the types of brain damage in head injury. Precautions were taken to prevent venesection haemolysis of blood samples. The samples were analysed on the day after venesection and were stored until then at $+4^{\circ} \mathrm{C}$. Statistical analysis was done from the recorded data. Mean, standard deviation, and standard error were calculated, and the comparisons between the groups were made using Student's $t$ test.

\section{Results}

The mean serum total lactate dehydrogenase (LDH) activity was $101.8 \mathrm{iu} / 1(\mathrm{SD} \pm 24.5)$ in the normal control group and $218.3 \mathrm{iu} / 1(\mathrm{SD} \pm 71.6)$ in the brain tumour control group. The range of LDH values in different groups of head injury is shown in the Table with the standard error of the mean LDH values. The mean LDH was higher than normal in the head-injured patients when the duration of unconsciousness was more than one hour and post-traumatic amnesia (PTA) exceeded one day, in all types of brain damage and in the disabled and dead groups on the first day of injury (Figs. 1-4).

Patients who were unconscious for less than one hour did not show a significant rise in LDH activity throughout the period of study. Patients who were unconscious for one hour to one day showed a statistically significant rise in LDH activity compared with the control group during the first day of injury $(t=5.6 ; \mathrm{df}=67 ; \mathrm{P}<0.001)$, the two to four day period $(t=3.11 ; \mathrm{df}=39$; $\mathrm{P}<0.01)$ and the five to nine day period $(t=2.29$; $\mathrm{df}=42 ; \mathrm{P}<0.05)$; there was no significant rise in the 10-15 day period. When the duration of unconsciousness was more than one day the rise of LDH activity was significant in comparison with the control level throughout the period of study $(t=9.36 ; \mathrm{df}=44 ; \mathrm{P}<0.001$ on the first day, $t=3.57$;

Table Lactate dehydrogenase values in patients with head injury

\begin{tabular}{|c|c|c|c|c|}
\hline \multirow[t]{2}{*}{ Group } & \multicolumn{4}{|l|}{$L D H$ activity } \\
\hline & $\begin{array}{l}\text { One day } \\
\text { mean } \pm S E \text { iu/l }\end{array}$ & $\begin{array}{l}2-4 \text { days } \\
\text { mean } \pm \text { SE iu/l }\end{array}$ & $\begin{array}{l}5-9 \text { days } \\
\text { mean } \leq E \text { iu/l }\end{array}$ & $\begin{array}{l}10-15 \text { days } \\
\text { mean } \pm S E \text { iull }\end{array}$ \\
\hline $\begin{array}{l}\text { Duration of unconsciousness } \\
\text { Less than one hour } \\
\text { One hour to } 24 \text { hours } \\
\text { More than one day }\end{array}$ & $\begin{array}{l}124.36 \pm 15.18 \\
217.81 \pm 20.28 \\
330.33 \pm 24.03\end{array}$ & $\begin{array}{l}147.65 \pm 44.57 \\
234.08 \pm 42.63 \\
275.83 \pm 48.64\end{array}$ & $\begin{array}{r}81.05 \pm 24.62 \\
182.23 \pm 34.86 \\
175.37 \pm 21.32\end{array}$ & $\begin{array}{r}53.87 \pm 35.65 \\
90.19 \pm 31.40 \\
217.51 \pm 25.73\end{array}$ \\
\hline $\begin{array}{l}\text { Duration of post-traumatic amnesia } \\
\text { Less than one hour } \\
\text { One hour to } 24 \text { hours } \\
\text { One day to one week } \\
\text { More than one week }\end{array}$ & $\begin{array}{r}81.92 \pm 13.92 \\
126.25 \pm 16.90 \\
216.31 \pm 20.07 \\
300.08 \pm 22.80\end{array}$ & $\begin{array}{r}29.25 \pm 29.34 \\
74.48 \pm 59.05 \\
192.98 \pm 35.94 \\
252.67 \pm 35.60\end{array}$ & $\begin{array}{rr}42.70 \pm 2.30 \\
40.03 \pm 13.62 \\
178.32 \pm 29.77 \\
241.99 \pm 39.87\end{array}$ & $\begin{array}{r}17.60 \pm 3.21 \\
55.60 \pm 24.87 \\
88.85 \pm 41.47 \\
167.00 \pm 31.98\end{array}$ \\
\hline $\begin{array}{l}\text { Type of brain injury } \\
\text { Concussion } \\
\text { Extracerebral haemotoma } \\
\text { Intracerebral damage } \\
\text { Brainstem injury }\end{array}$ & $\begin{array}{l}162.05 \pm 17.81 \\
238.71 \pm 52.33 \\
258.73 \pm 20.05 \\
344.40 \pm 33.24\end{array}$ & $\begin{array}{l}199.91 \pm 47.67 \\
178.24 \pm 72.12 \\
227.95 \pm 32.41 \\
307.08 \pm 101.73\end{array}$ & $\begin{array}{l}155.65 \pm 38.29 \\
162.80 \pm 85.84 \\
160.77 \pm 31.21 \\
284.77 \pm 140.72\end{array}$ & $\begin{array}{l}98.33 \pm 29.47 \\
\overline{140.73} \pm 39.72 \\
199.50 \pm 80.04\end{array}$ \\
\hline $\begin{array}{l}\text { Quality of survival } \\
\text { Good survival } \\
\text { Moderately disabled } \\
\text { Severely disabled } \\
\text { Dead }\end{array}$ & $\begin{array}{l}131.89 \pm 14.79 \\
243.16 \pm 19.47 \\
370.53 \pm 17.98 \\
323.26 \pm 29.19\end{array}$ & $\begin{array}{l}116.18 \pm 45.15 \\
273.52 \pm 26.08 \\
284.65 \pm 53.46 \\
278.02 \pm 79.53\end{array}$ & $\begin{array}{r}84.59 \pm 31.52 \\
235.48 \pm 36.30 \\
216.76 \pm 26.40\end{array}$ & $\begin{array}{r}66.21 \pm 34.36 \\
97.05 \pm 33.31 \\
207.63 \pm 33.92 \\
-\quad\end{array}$ \\
\hline
\end{tabular}




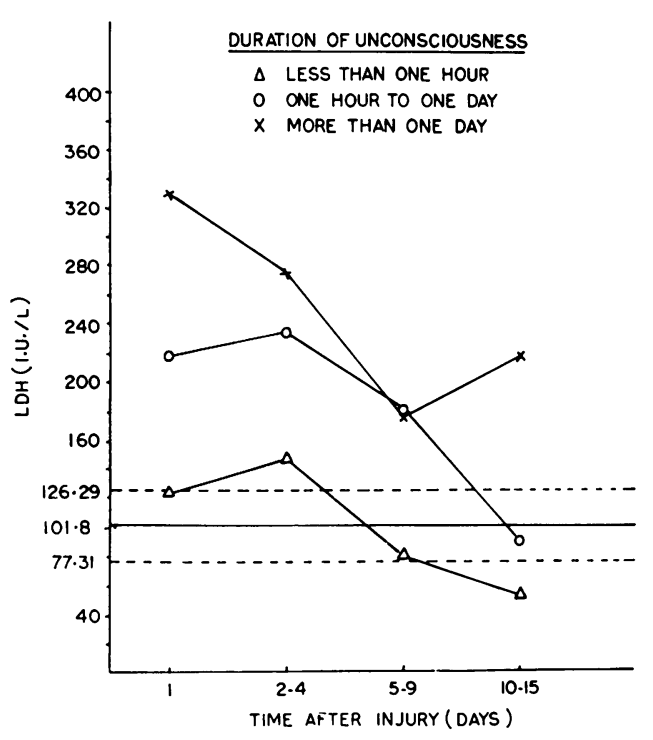

Fig. 1 Mean levels of serum total lactate dehydrogenase in head injury patients grouped according to duration of unconsciousness.

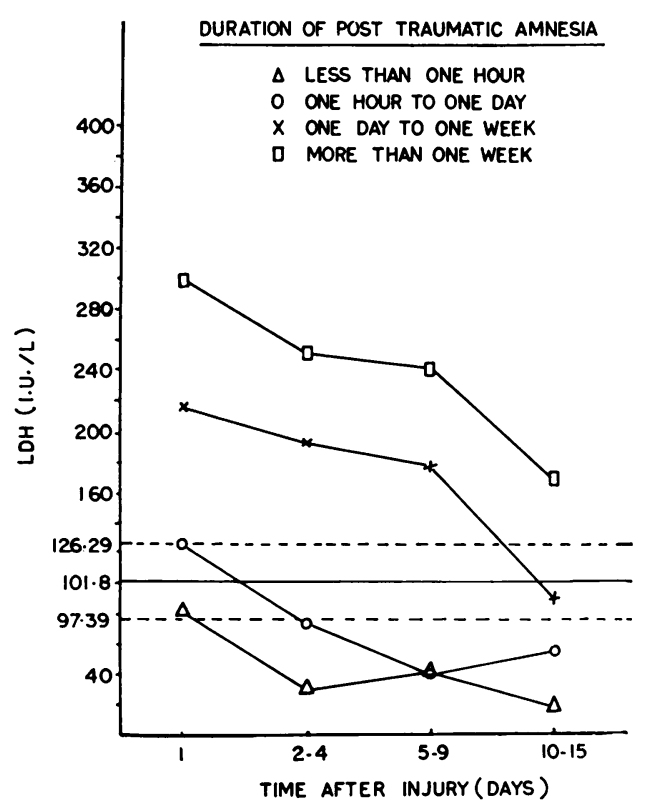

Fig. 2 Mean levels of serum total lactate dehydrogenase in head injury patients grouped according to duration of post-traumatic amnesia.

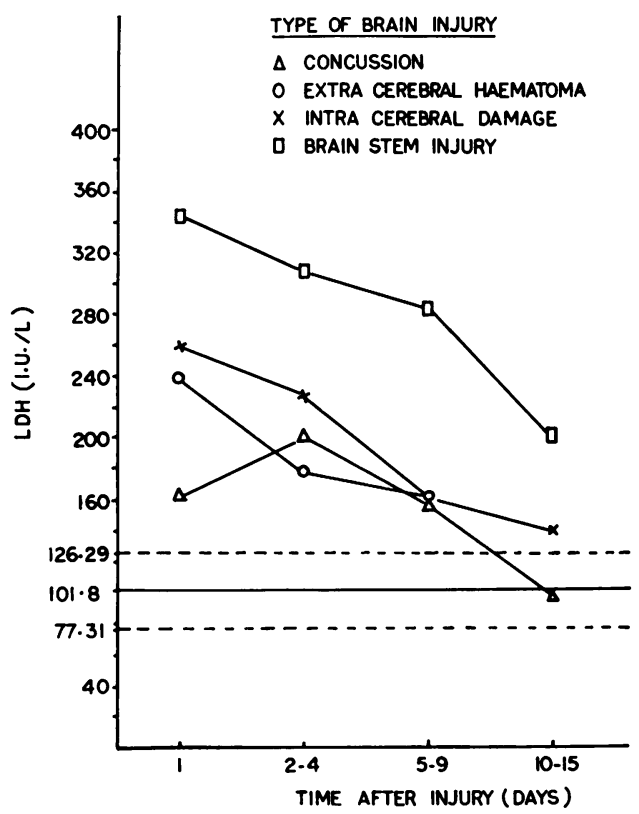

Fig. 3 Mean levels of serum total lactate dehydrogenase in head injury patients grouped according to type of brain damage.

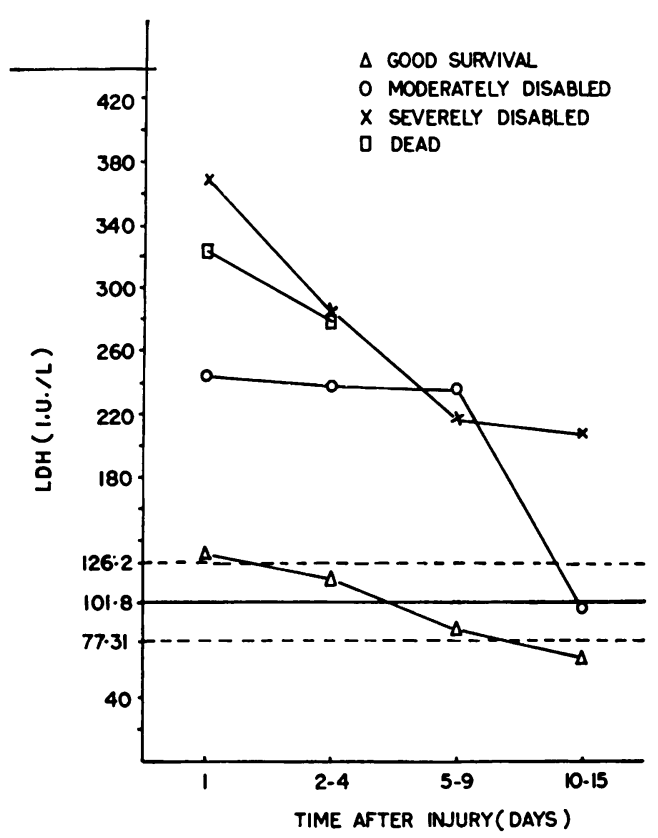

Fig. 4 Mean levels of serum total lactate dehydrogenase in head injury patients grouped according to outcome. 
$\mathrm{df}=34 ; \mathrm{P}<0.01$ during the two to four day period, $t=3.39 ; \mathrm{df}=33 ; \mathrm{P}<0.01$ in the five to nine day period, and $t=4.44 ; \mathrm{df}=34 ; \mathrm{P}<0.001$ in the $10-15$ day period). We also observed that patients who were unconscious for one hour to one day had a significant rise on the first day $(t=3.69 ; \mathrm{df}=62$; $P<0.001)$ and during the five to nine day period $(t=2.38 ; \mathrm{df}=21 ; \mathrm{P}<0.05)$ when compared with those who were unconscious for less than one hour. Patients who were unconscious for more than one day showed a significant rise of $\mathrm{LDH}$ activity on the first day of injury $(t=7.25 ; \mathrm{df}=39$; $\mathrm{P}<0.001)$, the five to nine day period $(t=2.9$; $\mathrm{df}=12 ; \mathrm{P}<0.02)$, and the $10-15$ day period $(t=$ $3.5 ; \mathrm{df}=10 ; \mathrm{P}<0.001$ ) when compared with those who were unconscious for less than one hour.

When the duration of post-traumatic amnesia was less than one day, the mean serum LDH level was normal or below the control level, and comparison was not made between this group and the control group. However, when the duration of post-traumatic amnesia was more than one day but less than one week, patients showed a significant rise of LDH activity on the first day $(t=5.42 ; \mathrm{df}=$ 53 ; $\mathrm{P}<0.001$ ), during the two to four day period $(t=2.52 ; \mathrm{df}=37 ; \mathrm{P}<0.02)$, the five to nine day period $(t=2.55 ; \mathrm{df}=40 ; \mathrm{P}<0.02)$, with no significant rise in the 10-15 day period. Patients with post-traumatic amnesia lasting for more than one week showed a significant rise in LDH activity throughout the period of study $(t=8.75 ; \mathrm{df}=57$; $\mathrm{P}<0.001$ on the first day, $t=4.21 ; \mathrm{df}=41 ; \mathrm{P}<0.001$ during the two to four day period, $t=3.5 ; \mathrm{df}=38$; $\mathrm{P}<0.01$ in the five to nine day period, and $t=2.03$; $\mathrm{df}=35 ; \mathrm{P}<0.05$ in the $10-15$ day period). Because of the apparent fall in the mean LDH activity below the control level in the groups with posttraumatic amnesia for less than one hour and less than one day, comparisons were not made between these groups and cases with post-traumatic amnesia for more than one day. Comparison of these groups revealed a significant difference only on the first day $(t=2,72 ; \mathrm{df}=52 ; \mathrm{P}<0.01)$.

Patients with concussion had a significant increase in serum LDH level on the first day $(t=3.29$; $\mathrm{df}=67 ; \mathrm{P}<0.01)$ and during the two to four day period $(t=2.05 ; \mathrm{df}=38 ; \mathrm{P}<0.05)$. Those with extracerebral haematoma showed a significant rise only on the first day $(t=2.61 ; \mathrm{df}=36 ; \mathrm{P}<0.02)$. Those with intracerebral damage had a significant rise during the first day $(t=7.65 ; \mathrm{df}=60 ; \mathrm{P}<0.001)$ and the two to four day period $(t=3.86 ; \mathrm{df}=43$; $P<0.001$ ), and those with brainstem injury had a significant rise on the first day $(t=7.24 ; \mathrm{df}=42$; $P<0.001)$ and during the two to four day period $(t=2.02 ; \mathrm{df}=31 ; \mathrm{P}<0.05)$. When the extracerebral haematoma group was compared with the concussion group the rise of LDH was not significant, whereas comparison of the groups with intracerebral damage and brainstem injury against the concussion group revealed a significant rise of LDH activity only on the first day of injury $(t=$ $3.6 ; \mathrm{df}=69 ; \mathrm{P}<0.001$ and $t=4.83 ; \mathrm{df}=51 ; \mathrm{P}<0.001$ respectively). The group with brainstem injury showed a significant rise of serum LDH only on the first day $(t=2.21 ; \mathrm{df}=44 ; \mathrm{P}<0.02)$ when compared to the intracerebral damage group. Patients with concussion, extracerebral haematoma, and intracerebral damage did not show a significant rise of serum LDH when compared with the brain tumour control group, whereas the brainstem injury group did show a significant increase in $\mathrm{LDH}$ activity on the first day of injury $(t=3.14 ; d f=22$; $\mathrm{P}<0.01$ ).

The group of patients with good survival registered no significant rise of serum LDH level throughout the period of study. The moderately disabled group recorded a significant increase on the first day $(t=7.09 ; \mathrm{df}=53 ; \mathrm{P}<0.001)$, in the two to four day period $(t=5.14 ; \mathrm{df}=39 ; \mathrm{P}<0.001)$, and the five to ten day period $(t=3.66 ; \mathrm{df}=39$; $\mathrm{P}<0.001$ ) when compared with controls. The severely disabled group showed a persistent significant rise throughout the period of study $(t=14.52$; $\mathrm{df}=43 ; \mathrm{P}<0.001$ on the first day, $t=3.41 ; \mathrm{df}=34$; $\mathrm{P}<0.01$ during the two to four day period, $t=4.3$; $\mathrm{df}=33 ; \mathrm{P}<0.001$ in the five to nine day period, and $t=3.1 ; \mathrm{df}=33 ; \mathrm{P}<0.01$ in the $10-15$ day period). In patients who died, there was also a consistent rise until the time of death $(t=7.51 ; \mathrm{df}=43 ; \mathrm{P}<0.001$ on the first day and $t=2.22 ; \mathrm{df}=33 ; \mathrm{P}<0.05)$ during the two to four day period when compared with controls. The moderately disabled group also showed a significant increase in serum LDH level on the first day $(t=4.22 ; \mathrm{df}=63 ; \mathrm{P}<0.001)$, during the two to four day period $(t=2.33 ; \mathrm{df}=18$; $\mathrm{P}<0.05)$ and the five to ten day period $(t=3.14$; $\mathrm{df}=19 ; \mathrm{P}<0.01)$ in comparison with the good survival group. When the severely disabled group was compared with the good survival group there was a significant rise in LDH level throughout the period of study $(t=10.25 ; \mathrm{df}=53 ; \mathrm{P}<0.001)$, on the first day $(t=2.41 ; \mathrm{df}=13 ; \mathrm{P}<0.05)$, during the two to four day period $(t=3.21 ; \mathrm{df}=13 ; \mathrm{P}<0.01)$, and the five to nine day period $(t=2.93 ; \mathrm{df}=9$; $P<0.01$ ). When the fatal group was compared with the good survival group the rise of LDH level was significant only on the first day $(t=5.86 ; \mathrm{df}=53$; $P<0.001$ ). Comparison of the moderately disabled and severely disabled groups showed significant statistical difference on the first day $(t=4.81$; $\mathrm{df}=38 ; \mathrm{P}<0.001)$ and during the $10-15$ day period 
$(t=2.32 ; \mathrm{df}=9 ; \mathrm{P}<0.05)$. There was also a significant difference on the first day $(t=2.28$; $\mathrm{df}=38$; $\mathrm{P}<0.05)$ when the moderately disabled group was compared with the fatal group, but the difference was not significant when the severely disabled group was compared with the fatal group.

\section{Discussion}

The results of the present study suggest that there is a definite correlation between an increase in serum LDH activity and the severity of head injury. When the duration of unconsciousness is less than one hour the activity of serum LDH is normal or below control level. But with a duration of unconsciousness exceeding one hour there is a corresponding increase in the LDH activity. Similarly, a rise in LDH activity is directly proportional to the duration of post-traumatic amnesia. Though the duration of unconsciousness and of post-traumatic amnesia are useful clinical criteria in assessment of the degree of brain damage at the bedside, important time will be lost in the management of head injury in the acute stage. In view of the close correlation between serum LDH level and duration of unconsciousness and post-traumatic amnesia, estimation of serum LDH can be used effectively to predict the extent of brain damage.

Lactate dehydrogenase activity varied with the type of brain damage. The level was high in brainstem injury and low in the concussion group. The activity was consistently high in intracerebral damage and brainstem injury. There was also a significant difference between cases with concussion and intracerebral damage, concussion and brainstem injury, and intracerebral damage and brainstem injury, but the difference was not significant when the extracerebral haematoma group was compared with other groups. Information regarding the type of brain damage can be inferred with some precision by using this enzyme assay.

Estimation of LDH activity is most useful in predicting the prognosis of head injury. High mean levels of LDH were found only on the first day in the good survival group, up to nine days in the moderately disabled group, and consistently throughout the period of study in the severely disabled and dead groups. It is also useful for differentiating the good survival group from other groups, and the moderately disabled group from the severely disabled and dead groups. However, no difference was detected between the severely disabled and dead groups.

Thomas and Rowan (1976) correlated the serum isoenzyme LDH-1 with the type of brain damage and the eventual outcome, and concluded that LDH-1 is raised after head injury. A similar conclusion was drawn by Lindblom and Aberg (1972). We found that the serum total LDH itself can give adequate information regarding the total extent of brain damage in head injury patients who have no extraneural injury. The total LDH is not specific for neural injury, and if extraneural injury is also present it is necessary to measure the level of LDH isoenzyme.

Lactate dehydrogenase, a cytoplasmic enzyme present in the brain, is released into the blood when the brain is injured, and its rise in the serum indicates the degree of brain damage. In cases of stroke or brain tumour when the blood brain barrier is broken, LDH is also released into blood. In our study the difference in rise of $\mathrm{LDH}$ was statistically significant when the brainstem injury group was compared with the brain tumour group on the first day of injury. We conclude that measurement of serum LDH can be used effectively in the management of head injury by indicating the extent and type of brain damage at an early stage, and in assessing the prognosis.

\section{References}

Dharker, S. R., Dharker, R. S., and Chaurasia, B. D. (1976). Lactate dehydrogenase and aspartate trans aminases of the cerebrospinal fluid in patients with brain tumours, congenital hydrocephalus and braino abscess. Journal of Neurology, Neurosurgery, and Psychiatry, 39, 1081-1085.

Editorial. (1973). Predicting outcome after severe brain? damage. Lancet, 1, 523-524.

Jennett, B., and Bond, M. (1975). Assessment of outcome after severe brain damage. Lancet, 1, 480-484.

King, L. R., McLaurin, R. L., and Knowles, H. C. (1974). Acid-base balance and arterial and CSF lactate levels following human head injury. Journal of Neurosurgery, 40, 617-625.

Lindblom, W., and Aberg, B. (1972). The pattern of S-LDH isoenzymes and S-GOT after traumatic brain injury. Scandinavian Journal of Rehabilitative Medicine, 4,61 .

Mohanty, S., Ramakrishna, Y. J., George, A., Rao, C. J., and Mukherjee, K. C. (1977). Autonomic disturbances in severe head trauma. Indian Medical Gazette, 17, 128-130.

Patra, D. K. (1977). A study of acid-base balance and lactate level in CSF and arterial blood following head injury. MS (Surgery) Thesis, Banaras Hindu University: Varanasi, India.

Rabow, L., Hebbe, B., and Lieden, G. (1971). Enzyme analysis for evaluating acute head injury. Acta Chirurgica Scandinavica, 137, 305.

Shukla, P. K., Sharma, D., and Mandal, R. K. (1978). Serum lactate dehydrogenase in detecting liver damage associated with pre-eclampsia. Journal of Obstetrics and Gynaecology, 85, 40-42. 
Tandon, P. N., Singh, B., Bhatia, R., and Banerjee, A. K. (1972). Electroencephalographic study of sleep in cases of prolonged unconsciousness. Neurology India, 20, 261-266.

Thomas, D. G. T., and Rowan, T. D. (1976). Lactic dehydrogenase isoenzymes following head injury. Injury, 7, 258-262.
Varley, H. (1969). Practical Clinical Biochemistry. Fourth edition, pp. 279-294. Heinemann: London. Wooton, I. D. P. (1964). Micro-analysis in Medical Biochemistry. Fourth edition, pp. 114-118. Churchill: London. 